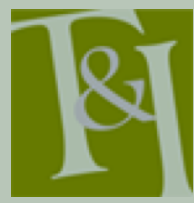

The International Journal for Translation \& Interpreting Research trans-int.org

\title{
Translating questionnaires for cross-national surveys: A description of a genre and its particularities based on the ISO 17100 categorization of translator competences
}

\section{Dorothée Behr}

GESIS - Leibniz Institute for the Social Sciences, Mannheim (Germany)

dorothee.behr@gesis.org

DOI: 10.12807/ti.110202.2018.a02

\begin{abstract}
Sound questionnaire translation is crucial for collecting equivalent data in cross-national surveys. The topic is widely discussed in fields in which translated questionnaires are used, such as in the social sciences or in cross-cultural psychology, but hardly in translation studies. This article aims at bridging this gap by bringing the genre of questionnaires closer to translation scholars and practitioners. To begin with, we will provide a sketch of key characteristics of cross-national survey methodology, with a special focus on questionnaire translation. Next, the multi-dimensional concept of translation competence will be introduced. Along the ISO 17100 competence model then, we will list requirements, challenges, and resources for questionnaire translation and illustrate those with examples. The concluding paragraph will highlight areas for interdisciplinary research involving both translation studies and cross-national survey methodology.
\end{abstract}

Keywords: Questionnaire translation, genre, translation competence

\section{Introduction}

Translation is a highly specialized activity that requires a set of diverse competences, ranging from linguistic and cultural, to subject-matter and toolrelated, to strategic and service-oriented ones. While many of these competences are general in nature and apply regardless of subject matter and text genre, it is generally recognized that the more a translator knows of a given subject matter - and relatedly, of any pertinent textual genres - the better he or she will be able to translate a given text. This article will outline requirements, challenges, and resources in questionnaire translation based on the ISO $17100^{1}$ categorization of professional competences of translators (see ISO, 2015). The translation and adaptation of questionnaires has long been a matter of extensive discussion in the social sciences (e.g., Harkness, 2003; Harkness, Villar, \& Edwards, 2010), in psychology ${ }^{2}$ (e.g., Hambleton, 2005; International Test Commission, 2017), in health research (e.g., Acquadro, Conway, Hareendran, \& Aaronson, 2008; Wild et al., 2009), and in business

\footnotetext{
${ }^{1}$ Reproduced by permission of DIN Deutsches Institut für Normung e.V. The definitive version for the implementation of this standard is the edition bearing the most recent date of issue, obtainable from Beuth Verlag GmbH, Burggrafenstraße 6, 10787 Berlin, Germany.

${ }^{2}$ In this field, the topic is discussed with an additional emphasis on assessment instruments, such as those measuring literary or numeracy competences. These instruments will not be specifically covered here; their particular translation and adaptation requirements are summarized, for instance, in a checklist provided by Hambleton \& Zenisky (2011).
} 
studies (e.g., Chidlow, Plakoyiannaki, \& Welch, 2014; Douglas \& Craig, 2007). When conducting cross-national studies, these disciplines rely on reliable, valid, and - most importantly - equivalent measurement instruments and data to draw sound conclusions. Against this backdrop, it is surprising that the various genres of research instruments, and particularly the questionnaire genre, have received scant attention in translation studies (exceptions include Behr, 2009; Bolaños-Medina \& González-Ruiz, 2012; Dorer, 2015; Ozolins, 2009; or Przepiórkowska, 2016). We will begin by providing an overview of key characteristics of cross-national survey methodology, with a special focus on questionnaire translation. Next, the multi-dimensional concept of translation competence will be introduced, using three competence models as an example. Drawing on the ISO 17100 competence model, we will then list requirements, challenges, and resources with respect to questionnaire translation and introduce examples to illustrate them. The concluding section will highlight areas for interdisciplinary research involving both translation studies and cross-national survey methodology. The ultimate goal of this article is to advance knowledge of the questionnaire genre and to encourage further contributions to the field. After all, knowledge of genres in contextual, conceptual, and linguistic terms is crucial in building translation competence and consequently in enhancing translation quality (e.g., García Izquierdo \& Borja Albi, 2008).

While we will concentrate on cross-national survey research in this article, the approaches and content equally apply to cross-cultural survey research within a single country (e.g., including diverse groups of migrants or several official languages) or to research and testing of individuals rather than larger groups. Furthermore, this article focuses on academic and particularly social science surveys and will use examples from these areas; we are not concerned with surveys from the field of market research, which may or may not apply the same procedures or criteria to the extent presented here.

\section{Cross-national survey methodology and questionnaire translation: A brief overview}

A survey is defined as a "systematic method for gathering information from (a sample of) entities for the purposes of constructing quantitative descriptors of the attributes of the larger population of which the entities are members" (Groves, Fowler, Couper, Lepkowski, Singer, \& Tourangeau, 2009, p. 2). The typical manner of gathering information is to ask questions of respondents. Given the impact that different wording and formatting of questions can have on the corresponding data (e.g., Schuman \& Presser, 1981), a standardized survey interview is crucial to the endeavour of collecting valid and reliable data from respondents. Validity and reliability are key concepts in survey research, with the former referring to "the extent to which the survey measure accurately reflects the intended construct" (Groves et al., 2009, p. 274) and the latter to "the consistency of measurement either across occasions or across items designed to measure the same construct" (Groves et al., 2009, p. 282). An entire discipline known as survey methodology has been developed around the task of how best to collect valid and reliable data, and a paradigm known as the total survey error paradigm has been conceived to systematically cover potential errors in the survey life cycle (Groves et al., 2009). Questionnaire design is only one of several phases that make up the survey life cycle. In this article, we will focus on this phase, as it has a direct relationship with the translation of questionnaires. ${ }^{3}$

\footnotetext{
${ }^{3}$ Sampling, data collection, and data processing are examples of other phases.
} 
Cross-national survey methodology builds on general monolingual survey methodology but includes several challenges that are unique to collecting survey data in different countries. ${ }^{4}$ The standardization approach known from general survey research, which calls for keeping (almost) everything identical in order to prevent methodological artefacts, applies to cross-national surveys as well, though sometimes to a lesser extent when there are country-specific differences that must be heeded (Harkness, 2008; Lynn, Japec, \& Lyberg, 2006). Nevertheless, the notion of standardization still informs the typical approach to developing and translating questionnaires to a great degree. This means that in deliberately designed cross-national surveys, a common source questionnaire is usually developed first (with adequate intercultural input), and it is then translated - rather than (culturally) adapted into the languages needed for a study. The assumption is that in this way, equivalent data ${ }^{5}$ can best be assured, even though an appropriate translation is no guarantee for measurement equivalence, which must be tested using statistical means after data collection has taken place (Davidov, Meuleman, Cieciuch, Schmidt, \& Billiet, 2014). There is a concern that unnecessary deviations from a source questionnaire will lead to differences in the results that are due to differences in the measurement instruments rather than to differences in any trait, attitude or opinion of interest. Harkness, Villar, and Edwards (2010) summarize the requirements that a translation in crossnational survey research is expected to fulfil as follows:

A successful survey translation is expected to do all of the following: keep the content of the questions semantically similar; within the bounds of the target language, keep the question format similar; retain measurement properties, including the range of response options offered; and maintain the same stimulus. Such matters as burden and form of disclosure are also meant to be kept constant. (pp. 117-118)

The fulfilment of these requirements depends, of course, on the suitability of the source questionnaire, both in terms of cultural relevance and translatability. If a survey is deliberately designed as a cross-national survey, these aspects can largely be taken on board during the development phase of a source questionnaire. In fact, an array of methods, including advance translations for checking translatability and cross-national pretests (Dorer, 2015; Fitzgerald, Widdop, Gray, \& Collins, 2011; Smith, 2003), are increasingly integrated into the process of source questionnaire development to ensure culturally relevant and smooth translations later on. To what extent a good translation is indeed sufficient to ensure equivalent data is yet another question; researchers regularly call for a greater degree of liberty in translation, for more cultural adaptation, and for empirical studies on how different translated vs. adapted versions impact the equivalence of data (e.g., Harkness, Schoua-Glusberg, \& Pennell, 2004; Harkness, Villar, et al., 2010; Kleiner, Pan, \& Bouic, 2009; Schwarz, 1997).

Over the years, translation quality has most notably been discussed in terms of translation assessment methods (Behr \& Shishido, 2016). In particular in the social sciences, the back translation approach, which has been popular since the 1970s and which originated from cross-cultural psychology (Brislin, 1970), has been replaced by team translation or the TRAPD model,

\footnotetext{
${ }^{4}$ Comprehensive state-of-the-art guidelines for conducting cross-national and cross-cultural research, including all phases of the survey life cycle, can be found here: http://ccsg.isr.umich.edu/ (October 31, 2107).

5 Similar to translation studies (Kenny, 1998), there are a multitude of definitions of equivalence used in cross-national and cross-cultural research (Johnson, 1998), referring to the ways in which data is collected, including different relationships between a source and a target questionnaire, or to the statistical properties of the data from one country in relation to the data from another country.
} 
as outlined further below. In its simplest form, back translation includes the transfer of the translation back into the source language and the subsequent comparison of the two source-language versions. Based on this comparison, conclusions are drawn as to the quality of the translation. Objections to this model, which may lead to overly literal translations and a false sense of security, have led to the development of the team model known as TRAPD (Harkness, 2003). TRAPD was developed for the European Social Survey (ESS), the flagship in the social sciences for the advancement of crossnational survey methods. ${ }^{6}$ The model has been adopted or adapted in many forms in other surveys. TRAPD stands for translation, review, adjudication, pretesting, and documentation. In its pure form, parallel translations are done by two skilled practitioners who work independently from each other (T). The translators then meet with survey and subject-matter experts to reconcile their versions and arrive at a final review version (R). Interdisciplinary collaboration is at the heart of the model, since a combination of translational, cultural, subject-matter, and survey research competences is regarded as crucial for producing a translation that is both a measurement instrument and a text "destined for discourse" (Harkness \& Schoua-Glusberg, 1998, p. 95). Depending on the set-up, another person - the adjudicator - may sign off on a reviewed translation in the adjudication phase (A). However, review and adjudication phases may also occur simultaneously. In addition, a translation should be thoroughly pretested among the target population $(\mathrm{P})$, as is also best practice in monolingual survey research. A pretest can be done qualitatively and/or quantitatively and should test whether respondents understand the questions in the intended sense, as well as the overall ease of understanding, the flow of the interview, data quality, etc. (Harkness, Pennell, et al., 2004). ${ }^{7}$ Documentation complements the process and includes documentation of staff profiles, translation and assessment procedures, translation challenges, particular decisions, and necessary adaptations (D) (Behr, Dept, \& Krajêeva, forthcoming; Harkness, Pennell, et al., 2004). The original TRAPD model explicitly speaks of "skilled practitioners" for the translation task, that is, experienced translators who should be hired, briefed, and trained specifically for questionnaire translation (Harkness, 2003, p. 36). In the latest version of the ITC guidelines for translating and adapting tests (ITC) (2017), which have been designed to widely influence translation and adaptation procedures in cross-cultural psychology, a translation and adaptation "expert" is defined as:

A person or a team with sufficient combined knowledge of (1) the languages involved, (2) the cultures, (3) the content of the test, and (4) general principles of testing, to produce a professional quality translation/adaptation of a test. (p. 12)

The guidelines further specify that, if translators do not possess knowledge of the principles of testing, they should be trained in these principles to ensure that they do not, for instance, render assessment tasks easier in their language compared to the other languages in a study. Given that much is at stake when translating research instruments - in brief, the validity of research conclusions and even possibly interventions based on these - the importance given to design characteristics of measurement instruments, both questionnaires and assessment tests, is understandable.

In the following, we will first introduce the idea of translation as a multidimensional concept. We will then present key survey features and questionnaire design characteristics that are of utmost importance for

\footnotetext{
${ }^{6} \mathrm{http}: / /$ www.europeansocialsurvey.org/ (October 19, 2017)

${ }^{7}$ For cross-cultural psychology and health research, quantitative validation based on larger samples is an integral part of the overall process of translation and adaptation of a measurement instrument (International Test Commission, 2017; Wild et al., 2009).
} 
questionnaire translation and apply in particular to this genre. We will present these using the ISO 17100 translator competence model as a structuring device. General aspects of translation competence that apply regardless of genre will not be covered.

\section{Translation competences - Different approaches}

Translation is a multi-dimensional concept. Translation competence models and approaches are manifold. They have received heightened attention over the past two decades, driven in particular through empirical studies with increasingly sophisticated study set-ups (Göpferich \& Jääskeläinen, 2009). In research, the empirically validated PACTE model is a prominent example (PACTE group, 2005). It differentiates between the strategic, the bilingual, the extra-linguistic, the instrumental, and the "knowledge about translation" subcompetences. For teaching, the EMT model (European Master's in Translation) has become a guiding principle for coherent, comparable, and high-standard training of translators Europe-wide (EMT experts, 2009). Its aim is to support and steer the development of the following competences among future translators: competence in translation service provision, language competence, intercultural competence, competence in information mining, thematic competence, and technological competence. Professional translators, and translation service providers in particular, are encouraged to follow the international standard ISO 17100 Translation services Requirements for translation services (2015), which specifies "requirements for all aspects of the translation process directly affecting the quality and delivery of translation services" (p. vi). It lists the competences that a professional translator should have. These are (and are described in the next section in more detail): translation competence; linguistic and textual competence in both the target and the source language; competence in the domain; competence in research, information acquisition, and processing; cultural competence; and technical competence.

While some conceptual and terminological differences exist between the EMT, PACTE, and ISO models, they by and large converge on required competences, in particular as regards the need for domain and textual knowledge. Hence, a preference for the ISO model in this article will not limit the applicability of the principles outlined further below. Furthermore, the various competences do not function as separate entities as they all interact with one another. For instance, domain competence goes hand-in-hand with textual knowledge, that is, knowledge of genres in the given domain. We will now define the ISO 17100 competences and, for each competence, describe particularities as applicable to questionnaire translation.

\subsection{ISO 17100: Translation competence}

Translation competence denotes the ability to produce a translation in compliance with the purpose of a translation and any given project requirements. Functionalist approaches to translation, which stress that the intended use of a translation should inform the translator's decisions (Nord, 2014), have thus made their firm imprint on the translation industry. Translators do not translate a questionnaire as-is, but rather a questionnaire that is embedded in a larger research context with specific requirements. If these requirements are not provided by the commissioner, a translator must actively request this information. As Table 1 shows (adapted from Behr, Braun, \& Dorer, 2016), we can broadly differentiate between instrumental questionnaire translation and documentary questionnaire translation. An instrumental translation is firmly embedded in a new target culture and can serve any text function a non-translated text can achieve, while a documentary 
translation documents a situation from the source culture and is a "kind of metatext marked as a translation" (Nord, 1997, p. 52). Instrumentally translated questionnaires are all questionnaires that will eventually collect data. If a source questionnaire is the result of a careful questionnaire development phase that includes different layers of intercultural input (Dean, Caspar, McAvinchey, Reed, \& Quiroz, 2007; Smith, 2003) ${ }^{8}$, such a questionnaire is often submitted for translation rather than adaptation. Adaptations, understood as intentional deviations that go beyond linguistic changes, are typically earmarked (e.g., for questions on education or the political party system in a country) or only allowed upon request (scenario I). One reason for this is that standard statistical procedures applied in data analysis require that the items surveyed be the same (Harkness, van de Vijver, \& Johnson, 2003) and, up to the present, sameness has been based on a rather narrow definition of translation. If a questionnaire that has been developed for use in a specific country requires translation so that it can be used somewhere else, there is probably a need for a greater degree of adaptation (scenario II). This is also why the umbrella term adaptation is often used to denote the overall process in cross-cultural psychology and health settings, where questionnaires are often adopted and adapted from other countries (Behr \& Shishido, 2016; see also International Test Commission, 2017). Nevertheless, certain constraints on adaptation apply to scenarios I and II if comparability between the data collected in diverse settings is envisaged. They apply to a lesser degree or not at all if comparability is not planned (scenarios III and IV).

Documentary translation, in comparison, documents what has been asked in a given country - the translation is not adapted for use in another country (scenario V). For instance, the German General Social Survey (ALLBUS) is translated into English to allow international researchers who do not speak German to learn about the content of the questions asked in Germany. ${ }^{9}$ The questionnaires of the Dutch LISS panel are translated into English for the same reasons. ${ }^{10}$

Table 1: Different Scenarios for Questionnaire Translation (adapted from Behr et al., 2016)

\begin{tabular}{|c|c|c|c|}
\hline & \multicolumn{2}{|c|}{ Instrumental translations } & \multirow{2}{*}{\begin{tabular}{l}
\multicolumn{1}{c}{$\begin{array}{c}\text { Documentary } \\
\text { translation }\end{array}$} \\
Comparability with \\
source \\
questionnaire \\
planned
\end{tabular}} \\
\hline & $\begin{array}{l}\text { Comparability with source } \\
\text { questionnaire planned }\end{array}$ & $\begin{array}{l}\text { Comparability with } \\
\text { source } \\
\text { questionnaire not } \\
\text { planned }\end{array}$ & \\
\hline $\begin{array}{l}\text { Source } \\
\text { questionnaire } \\
\text { designed with a } \\
\text { view to cross- } \\
\text { national } \\
\text { application }\end{array}$ & $\begin{array}{l}\text { I: Adaptation may be } \\
\text { necessary; permissible } \\
\text { adaptations are often } \\
\text { identified in advance; further } \\
\text { adaptations are usually } \\
\text { subject to approval. }\end{array}$ & $\begin{array}{l}\text { III: Adaptation may } \\
\text { be necessary, no } \\
\text { constraints }\end{array}$ & $\mathrm{n} / \mathrm{a}$ \\
\hline $\begin{array}{l}\text { Source } \\
\text { questionnaire } \\
\text { designed for a } \\
\text { specific country }\end{array}$ & $\begin{array}{l}\text { II: Adaptation may be } \\
\text { necessary; however, they } \\
\text { may be constrained by the } \\
\text { comparability requirement. }\end{array}$ & $\begin{array}{l}\text { IV: Adaptation may } \\
\text { be necessary, no } \\
\text { constraints }\end{array}$ & $\begin{array}{l}\text { V: No adaptation; } \\
\text { questionnaire remains } \\
\text { embedded in source } \\
\text { culture. }\end{array}$ \\
\hline
\end{tabular}

\footnotetext{
${ }^{8}$ Examples include the European Social Survey (ESS), the International Social Survey Program (ISSP), the OECD studies PISA (Programme for the International Assessment of Adult Competencies) and PIAAC (Programme for the International Assessment of Adult Competencies), and SHARE (Survey of Health, Ageing and Retirement in Europe).

${ }^{9} \mathrm{https}$ ://www.gesis.org/en/allbus/contents-search/questionnaires/ (October 20, 2017)

${ }^{10} \mathrm{https}: / /$ www.dataarchive.lissdata.nl/study_units/view/1 (October 20, 2017)
} 
Furthermore, besides a general assignment to one of the scenarios I-V, each single project will have its own specifications (e.g., regarding target group, survey mode, consistency with prior waves of a study, or cross-links to other studies). Translation competence then allows professional translators to meet the needs of a given survey translation project - and also to voice their concerns when they fear that cultural and linguistic aspects of the target population are not adequately met.

\subsection{ISO 17100: Linguistic and textual competence in both the target and the source language}

Linguistic and textual competence in both the target and the source language denotes the ability to appropriately understand the source language, to fluently render text in the target language, and to apply general and genre-specific conventions. While the ability to understand the source text and to render it fluently in the target language is a goal for most types of translations, translators of questionnaires face certain obstacles or challenges in these regards. Contrary to many other genres, questions in questionnaires are often asked without much context that could help to disambiguate their meaning. Hence, it is not surprising that translators may not always perceive the intended meaning of a question or not always perceive as salient what a native speaker of the source language would perceive as salient (Harkness, Pennell, et al., 2004). Hence, team approaches to translation as well as translation annotations that supplement a questionnaire by indicating the intended meaning of a term or the definition of a concept are increasingly used in survey research (Behr \& Scholz, 2011). Producing a fluent translation calls for producing a questionnaire that is as easy and clear to understand as possible, and this applies in particular to general population surveys. This requirement places heavy demands on the clarity of syntax and simplicity of wording. Although pretesting - in particular, cognitive interviewing ${ }^{11}$ - is used as a means of testing the comprehensibility of the translated questions, this does not eliminate the need for translators to strive for a high degree of clarity in the target language. Anecdotal evidence suggests that some translators may strive instead for a high level of formality, possibly in an attempt to show and prove their expertise. Depending on the language and the different registers available in this language, such attempts may run counter to the general comprehensibility of questions among all population groups, including those with lower education levels. Translators also need to take into account that in interviewer-administered surveys, an interviewer usually reads out the questions only once. Thus, translations should aim for clarity and a reading flow, otherwise the interviewer may (in-)advertently change the question when administering the survey, endangering data comparability across a survey and, in a cross-national context, across countries. Additionally, there are certain basics that translators should be aware of and that can be subsumed under knowledge of genre-specific conventions. These will be detailed in the next section.

\subsection{ISO 17100: Domain competence}

Domain competence denotes the ability to understand the content of the source language and to reproduce it in accordance with appropriate style and terminology. Here, we will not delve into domains such as medical, legal or business, but rather present knowledge on questionnaires as measurement and research instruments - knowledge that is deemed to be highly useful as

\footnotetext{
${ }^{11}$ Cognitive interviews are typically face-to-face interviews in which the think-aloud method or follow-up questions, called probes, are used to elucidate the response process leading up to a survey answer (Beatty \& Willis, 2007).
} 
background information for those translating questionnaires. Of course, knowledge of the topics and concepts covered in a survey (e.g., on health or personality) is also regarded as valuable for producing appropriate translations. The team translation approach outlined above brings together translators and subject-matter experts in review discussions so that different types of competences can be brought to the discussion table. Thus, each individual involved does not need to possess all the required competences (see also International Test Commission, 2017, in this regard).

In methodologically sound approaches to questionnaire development, survey questions are not the starting point of research but rather the product of the process of operationalization. In other words, questions are the end of a chain that involves clarifying research objectives (e.g., importance of religion in today's society), elaborating theoretical concepts (e.g., religiosity), identifying empirical indicators (e.g., frequency of church visits), and "translating" these indicators into specific questions that can be understood in the intended manner and consistently by all respondents (e.g., "Apart from special occasions such as weddings and funerals, about how often do you attend religious services nowadays?") (Schwarz, 1997). Hence, the way a question is eventually worded is closely linked to the research goals. Unnecessary changes to a question when translated into another language are thought to be threatening both to the notion of standardization across respondents and countries as well as to the operationalization of a concept. Typically, questions and questionnaires are constructed in an iterative process, taking several rounds and including expert discussions and reviews as well as testing procedures.

As with translation, the writing of questions and designing of questionnaires had long been considered an art more than a science. With the development of cognitive labs, the use of think-aloud and probing techniques, the 1980s then saw the beginning of the cognitive movement, which helped underpin the question-answer process of a respondent with various cognitive and communication theories and models. Fowler \& Cosenza (2008) summarize this question-answer process as follows: (1) understanding a question, (2) having or retrieving information needed for answering the question, (3) "translating" the relevant information into the form required for an answer, and (4) providing the information by writing, entering or telling the answer. Such categorizations have been the starting point for guidelines for effective question writing. Based on Fowler \& Cosenza (2008), Table 2 lists selected general guidelines on the one hand and comments on specific needs in translation on the other hand. Here we focus on (1) aspects that may prevent respondents from understanding a question in the intended way, (2) aspects that may hinder the retrieval of relevant information, and (3) aspects that are important for ensuring the response task. It must be noted that within the constraints of this article, conceptual aspects underlying question and questionnaire development cannot be treated exhaustively. ${ }^{12}$ The key message for translators is: that which applies to questions and questionnaires in general typically applies to translation and the translated instruments as well. Thus, the guidelines informing general survey research can provide an orientation for the translation process as well.

Response scales and their translation are in fact much more diverse and complex than suggested in Table 2, section 3. For instance, scales, when devised as rating scales, can be deliberately designed to be bipolar (two opposing sides, e.g., "good"/"bad") or unipolar (from zero to negative or positive, e.g., a frequency scale running from "never" to "always"). They can be crafted with a different number of scale points (e.g., four or five response

\footnotetext{
${ }^{12}$ More detailed insights into response processes and questionnaire design recommendations are provided by Dillman, Smyth, and Christian (2008) and Tourangeau, Rips, and Rasinksi (2000).
} 
Table 2: Selected Guidelines for Writing Effective Questions and Their Relevance for Translation (after Fowler \& Cosenza, 2008)

\begin{tabular}{|c|c|c|}
\hline & Aspect & Comments with respect to translation \\
\hline a & $\begin{array}{l}\text { Unfamiliar or complex words or } \\
\text { phrases. }\end{array}$ & $\begin{array}{l}\text { Translators need to be aware of the target population of a } \\
\text { survey and their way of speaking to make appropriate } \\
\text { decisions regarding register and wording. }\end{array}$ \\
\hline $\mathrm{b}$ & $\begin{array}{l}\text { Lack of a time frame (e.g., "in the } \\
\text { past } 2 \text { weeks"). }\end{array}$ & $\begin{array}{l}\text { Translators need to be aware of words indicating time } \\
\text { frames or words otherwise indicating a consistent } \\
\text { framework within which to answer (e.g., "in total," "in } \\
\text { general" or "nowadays"). These words should not be } \\
\text { omitted. Experience shows that when not aware of the } \\
\text { genre-specific conventions, translators tend to omit such } \\
\text { words. }\end{array}$ \\
\hline c & $\begin{array}{l}\text { Embedded assumptions that may not } \\
\text { apply (e.g., "Because of the increase } \\
\text { in juvenile crime, do you think that } \\
\text { the school day should be longer?"). }\end{array}$ & $\begin{array}{l}\text { Assumptions may work in one cultural context but not in } \\
\text { others; translators should speak up when assumptions do } \\
\text { not apply (see section } 3.5 \text { on cultural competence in this } \\
\text { regard). }\end{array}$ \\
\hline $\mathrm{d}$ & $\begin{array}{l}\text { Asking multiple questions at the } \\
\text { same time, so-called double-barreled } \\
\text { questions (e.g., "Do you want to be } \\
\text { rich and famous?"). }\end{array}$ & $\begin{array}{l}\text { Translators may sometimes need to become more specific } \\
\text { and explicit for linguistic reasons; however, they should } \\
\text { always consider whether or to what extent this may have } \\
\text { an effect on the response process and on comparability. }\end{array}$ \\
\hline \multicolumn{3}{|c|}{ 2. Aspects that may hinder the retrieval of relevant information } \\
\hline & Aspect & Comments with respect to translation \\
\hline $\mathrm{a}$ & Lack of information. & $\begin{array}{l}\text { What is common knowledge in one cultural context is not } \\
\text { necessarily common knowledge in another context; } \\
\text { translators should speak up when assumed knowledge } \\
\text { does not exist in their country (see section } 3.5 \text { on cultural } \\
\text { competence in this regard). }\end{array}$ \\
\hline b & $\begin{array}{l}\text { Asking for information in a way that } \\
\text { might be unfamiliar to the } \\
\text { respondent. }\end{array}$ & $\begin{array}{l}\text { This may also be a candidate for necessary adaptations. } \\
\text { An often cited example is that of "walking several blocks," } \\
\text { which was converted into a metric distance of "several } \\
\text { hundred meters" by Bullinger et al. (1998) for the German } \\
\text { version of the instrument (see section } 3.5 \text { on cultural } \\
\text { competence in this regard). }\end{array}$ \\
\hline
\end{tabular}

3. Aspects that are important for ensuring an effective response task

\begin{tabular}{|l|l|l|}
\hline & Aspect & Comment \\
\hline a & $\begin{array}{l}\text { Clarifying the response task (e.g., "How many } \\
\text { months ago ..." rather than "How long ago did } \\
\text { you ...") to indicate the desired answer format } \\
\text { (here: months). }\end{array}$ & $\begin{array}{l}\text { Translators should be aware of the relationship } \\
\text { between response options(s) and question } \\
\text { wording. }\end{array}$ \\
\hline b & $\begin{array}{l}\text { Questions and response options that match } \\
\text { (e.g., if a question asks how likely it is that a } \\
\text { course will be attended, the options should be } \\
\text { presented in terms of likelihood, such as "very } \\
\text { likely" and "somewhat likely," and not in terms of } \\
\text { some other dimension, such as "definitely," } \\
\text { "probably," and "not sure"). }\end{array}$ & See above. \\
\hline c & $\begin{array}{l}\text { Indicating the response range in the way a } \\
\text { question is worded (e.g., if one is interested in } \\
\text { different degrees of concern about an operation, } \\
\text { the questions should ask, "How many concerns } \\
\text { do you have?" rather than "Do you have } \\
\text { concerns?). The latter would suggest a yes/no } \\
\text { answer. }\end{array}$ & See above. \\
\hline d & $\begin{array}{l}\text { Having response categories that are mutually } \\
\text { exclusive and exhaustive, i.e., there should be } \\
\text { no overlap between response options, and the } \\
\text { given response options should cover the full } \\
\text { range of possible responses. }\end{array}$ & $\begin{array}{l}\text { This category becomes particularly pertinent for } \\
\text { numerical frequency scales where the } \\
\text { translation should mirror the same frequency } \\
\text { ranges given in the source text without } \\
\text { producing overlap across categories. }\end{array}$ \\
\hline
\end{tabular}


options), with extreme or less extreme labels at the ends (e.g., "extremely satisfied" vs. "very satisfied"), with (assumed) equidistance between scale points (which is important for statistical analyses later on), or symmetry between labels (e.g., the qualifiers "very" and "somewhat" on both the negative and the positive side of a scale). Since response scales record the respondent's answer, which then becomes part of the statistical data, response scales are at the heart of measurement. Much methodological research has been devoted to response scales and the effects of different scales on the resulting data, both in general and in cross-national survey research. In principle at least, the translation should mirror the decisions by the researcher to the extent possible. For instance, an extreme end point ("extremely satisfied") suggests to the respondent that nothing can go beyond this point, and this should be mirrored in the translation. At the same time, it is known that scale translation is what causes most intended or unintended deviations from the source version for both linguistic and cultural reasons. It is in precisely this field where research is urgently needed on whether adherence to stimulus, if linguistically possible, indeed brings the desired measurement equivalence or whether striving for equivalence of effects would be the better option (Behr, 2009; Harkness, Pennell, et al., 2004; Harkness, Villar, et al., 2010; see Behr \& Shishido, 2016, for adaptations of scales for the Japanese context).

The science of asking questions not only concerns individual questions but also the construction of the questionnaire as a whole. For translators, it is crucial to understand the potentially non-linear flow of questionnaires caused by filters or routing, which instruct and/or force respondents to skip questions as a result of answers given earlier in the questionnaire. The consequence of this is that the linear sequence, as shown in a source questionnaire to be translated, is not necessarily the sequence in which a respondent receives the questions. An understanding of such construction principles is particularly important when it comes to ensuring consistency in wording and terminology as well as interview flow. Furthermore, computer-administered surveys, whether read out by an interviewer or read by the respondents themselves, may make use of so-called dynamic texts. This means that an answer provided earlier in the questionnaire is automatically inserted at the right position in another question, e.g., the year the current job was started or health complaints mentioned earlier in the survey. Once again, the underlying logic needs to be understood, and the translator then has the task of making this logic work in the target language context, which may at times call for in-depth collaboration between survey programmers and translators.

Of course, it is the researcher who is first and foremost responsible for crafting effective questions and questionnaires, while the translator must take care that these measurement properties and decisions are not lost in translation. When researchers design cross-national surveys, carefully developing a questionnaire with cross-national implementation in mind will enable the rendering of more comparable translations. Nevertheless, as linguistic systems are set up differently and communications conventions diverge, it is not always possible to convey everything in identical fashion across countries (Harkness, Villar, et al., 2010). This is where we come back to the tenet that translation is always a decision-making process taking into account aspects of comparability, linguistic requirements of the target language, measurement characteristics of the source questionnaire, and overall project specifications (Behr, 2009).

Furthermore, different modes of survey implementation must be considered. At a basic level, we can differentiate between the intervieweradministered and the self-administered modes. These modes can be further broken down into face-to-face and telephone interviews and paper-and-pencil and web-based surveys, respectively. Each of these surveys has its own 
requirements beyond a common core. These requirements can include: instructions addressed to the interviewer in interviewer-administered surveys or instructions addressed to the respondent in self-administered surveys; different layout features (e.g., interface buttons vs. paper layout that call(s) for different instructions to "select, press or check" an answer); different anchorages in time or space (e.g., "in the following" may be understood in a temporal sense in interviewer-administered surveys and in a spatial sense in self-administered surveys); and different ways of accommodating language differences due to gender or different forms of address. For example, in a selfadministered paper-and-pencil questionnaire, questions in French may use wordings such as "satisfait(e)" to address both genders, whereas the same questionnaire for a web-based survey may be programmed twice - once for female respondents and once for male respondents. In contrast, the questionnaire for an interviewer-administered survey might function without any gender reference due to interviewers being trained on how to administer the interview.

\subsection{ISO 17100: Competence in research, information acquisition, and processing}

Competence in research, information acquisition, and processing denotes the ability to efficiently search for any information (linguistic, subject-matter, etc.) needed for understanding the source text and for rendering it in the target language. Beyond the usual print and online, multilingual and monolingual (web) resources, it is advisable for survey translators to be cognizant of national and international data archives and survey project websites where questionnaires (and translations) of prior survey waves are often made available. In order to maintain consistency within a survey project in particular, access to previous translations from that project is desirable. For surveys that are fielded at regular intervals, translations should not be changed unless serious mistakes are identified that have an effect on data comparability. Particularly when drawing on project-external resources (i.e., translations from other surveys), translators should always be wary and vet those existing resources for quality and appropriateness for a given survey project. In addition, questionnaires from national, monolingual surveys stored in data archives or on survey project websites may serve as parallel texts, which can support translation decisions by providing common translations of "don't know" or "refused" answer categories as well as ideas and suggestions for scale labels in a given language.

Given the importance of simplicity and clarity of wording, corpora may also be a valuable source for questionnaire translators (see in particular Mahadi, Vaezian, \& Akbari, 2010, for an introduction to corpora). A corpus is a collection of authentic texts that are available in machine-readable form and that are sampled to be representative of the language under study. Corpora in one's mother tongue - for instance, a general reference corpus that is homogenous and comprehensively represents a language - may help to assess the level of difficulty of terms (as indicated by word frequency) and hence their suitability for a given target population of a survey. Corpora may also be used for assessing the adequacy of collocations in a given language. In surveys, collocations play a key role in response scales where qualifier and adjective or verb are often combined, such as in a scale labelled "extremely dangerous," "very dangerous," "somewhat dangerous," etc. The translation of response scales comes with many demands (Harkness, Pennell, et al., 2004; Harkness, Villar, et al., 2010; Behr, 2009), collocations being one of them, and corpora can provide useful linguistic insights in this regard (Przepiórkowska \& Zmijewska-Jedrzejczyk, 2013). 


\subsection{ISO 17100: Cultural competence}

Cultural competence denotes the ability to apply knowledge of both the source and the target cultures to the translation process (e.g., knowledge of behavioural standards or value systems). We have indicated above that, ideally, intercultural input should shape the development of a source questionnaire in a deliberately designed cross-national survey so that the constructs and the question content are equally relevant everywhere. Dorer (2011) reports, for instance, on a definition in a questionnaire item stating that "community service refers to a sentence OTHER than a prison sentence or fine where the offender is asked to perform a task or tasks that benefit the community e.g. cleaning litter from the streets" (p. 20). During the development of the source questionnaire, the example ("cleaning litter from the streets") was deleted following a country's comment that this type of community service in a public space does not exist in their country. Dept (2013) provides the following as an example of an item that needs to be critically examined from a cultural point of view, especially if, in the envisaged cultures of a study, such types of body language are not common: "I don't mind handshakes but a hug from a casual acquaintance is a bit too much for me" (p. 9). In general, topics that are heavily ingrained in a culture are challenging to ask across countries and will necessarily become more abstract in order to meet the needs of many countries (e.g., questions on the perceptions of a legal system in a country ${ }^{13}$ or on religion ${ }^{14}$ ). The better a questionnaire is prepared for cross-cultural implementation, the fewer adaptations will be needed. Nevertheless, translation teams should always be wary and speak up if concerned about the suitability of a question. The last step of the TRAPD translation model calls for documentation. Cultural adaptations are among those elements that require documentation for internal monitoring, but this documentation is also necessary for providing transparency to data users, who will need to know how questions that will become part of their analyses relate to the source text (Behr, Dept, \& Krajceva, forthcoming). If a questionnaire translation is done based on a questionnaire that has originally been developed with only one culture - rather than with cross-cultural implementation - in mind, a certain number of cultural adaptations are often needed. Oude Voshaar, ten Klooster, Taal, Krishnan, and van de Laar (2012) report on the Dutch translation and validation among arthritis patients of the PROMIS physical function item bank, which had originally been developed in the US. Here, for instance, the item "Are you able to push open a door after turning the knob?" needed to be culturally adapted into a version along the lines of "Are you able to push open a door after pushing down the latch?" due to the Netherlands having different door operating mechanisms (p. 4). Cultural adaptations should always be guided by the measurement goals and the construct(s) researchers have in mind - which often requires additional competences from subject-matter experts in the relevant fields.

\subsection{ISO 17100: Technical competence}

Technical competence denotes the knowledge of, and skills to use, technical resources (tools, IT systems) in the production of a translation. In principle, this is not different from other textual genres. Large-scale studies, such as the ESS or PISA or PIAAC, often use their own tools and platforms or a combination of existing resources and tailor-made resources so that translators will likely need to familiarize themselves with new tools. The creation of new tools mainly results from the need to ensure smooth integration with the survey software, accommodation of multi-step translation processes (as

\footnotetext{
${ }^{13}$ ESS: http://www.europeansocialsurvey.org/data/themes.html?t=justice (October 29, 2017)

${ }^{14}$ ISSP: https://www.gesis.org/issp/modules/issp-modules-by-topic/religion/ (October 29, 2017)
} 
outlined in section 2), and the documentation needs that are part of best practice in survey research. Thus, an understanding of these aspects will help translators to more efficiently familiarize themselves with tailor-made survey translation tools.

\section{Conclusions and outlook}

This article matches selected characteristics of surveys and questionnaires to translator competences, and yet it can only serve as a first step. The goal is to incite translators not familiar with the genre to become aware of the factors guiding the actual wording of questions, of how questionnaire translation is situated between fluency and comparability requirements, and of how translation errors or unwarranted deviations may impact data comparability. Contrary to other genres, there is not much standardization across the myriad of questionnaires in existence; even the well-known agree-disagree scale with which many of us are familiar comes in different guises, with a different number of scale points, differently labelled response options, or different existing translations. Furthermore, the scientific and theoretical basis that undergirds good questionnaire design in general and cross-national surveys in particular is constantly evolving. Nevertheless, it is important for translators to be aware of comparability needs in cross-national surveys in general, of the principles of concept operationalization, of current models depicting the question-response process, and of resulting question guidelines so that they can identify in each individual questionnaire the different structural elements that make up the questionnaire, implicit and explicit measurement characteristics of the questions, as well as relationships between different questions.

While translators must familiarize themselves with (cross-national) survey methodology, survey researchers will also need to familiarize themselves with the modern theories, approaches, and benchmarks used in translation studies. Too often, a literal notion of translation still prevails, since an informed understanding of what good translation involves is lacking (Bolaños-Medina \& González-Ruiz, 2012; Harkness, Villar, et al., 2010).

Finally, an important research gap that can best be filled by interdisciplinary cooperation is that of how far a translation can deviate or even must deviate in order to ensure measurement equivalence. This question relates to principles of questionnaire design, touches upon the notions of good translation, and is also closely related to the divide between adaptations and translations. However, the issue of granting more leeway for translations and adaptations cannot be answered by translators or translation scholars alone. In the end, statistical procedures, in concert with qualitative (pretesting) procedures, will have the final say on equivalence (levels) of questions and scales (Davidov et al., 2014). Thus, both disciplines, translation studies and cross-cultural survey methodology, should cooperate in order to further this research strand and improve knowledge on cross-national studies. With such cooperation, we can hope that the challenges inherent in questionnaire translation can be tackled and minimized to the benefit of many. After all, "in decades of writing about cross-national and multinational research, language and translation issues are almost inevitably presented as serious challenges" (Harkness, Villar et al., 2010, p. 117).

\section{References}

Acquadro, C., Conway, K., Hareendran, A., \& Aaronson, N. (2008). Literature review of methods to translate health-related quality of life questionnaires for use in 
multinational clinical trials. Value in Health, 11, 509-521. Retrieved from http://www.valueinhealthjournal.com/article/S1098-3015(10)70019-X/pdf

Behr, D. (2009). Translationswissenschaft und international vergleichende Umfrageforschung. Qualitätssicherung bei Fragebogenübersetzungen als Gegenstand einer Prozessanalyse. (Doctoral dissertation, Bonn: GESIS. http://nbn-resolving.de/urn:nbn:de:0168-ssoar-282120)

Behr, D., Braun, M., \& Dorer, D. (2016). Measurement instruments in cross-national surveys. GESIS Survey Guidelines. Mannheim: GESIS - Leibniz institute for the Social Sciences. Retrieved from: http://nbn-resolving.de/urn:nbn:de:0168-ssoar261259

Behr, D., Dept, S, \& Krajêeva, E. (forthcoming). Documenting the survey translation and monitoring process. In T. Johnson, B.-E. Pennell, I. Stoop, \& B. Dorer (Eds.), Advances in comparative survey methods: Multinational, multiregional and multicultural contexts (3MC). New York: John Wiley \& Sons.

Behr, D., \& Scholz, E. (2011). Questionnaire translation in cross-national survey research: On the types and value of annotations. mda: Methoden, Daten, Analysen, 5(2), 157-179. Retrieved from https:/www.gesis.org/fileadmin/ upload/forschung/publikationen/zeitschriften/mda/Vol.5_Heft_2/MDA_2011_2_ Fb_1_Behr_Scholz.pdf

Behr, D., \& Shishido, K. (2016). The translation of measurement instruments for cross-cultural surveys. In C. Wolf, D. Joye, T. W. Smith, \& Y. Fu (Eds.), The SAGE handbook of survey methodology (pp. 269-287). London: Sage.

Beatty, P. C., \& Willis, G. B. (2007). Research synthesis: The practice of cognitive interviewing. Public Opinion Quarterly, 71, 287-311. Retrieved from https://academic.oup.com/poq/article/71/2/287/1928986/Research-SynthesisThe-Practice-of-Cognitive

Bolaños-Medina, A., \& González-Ruiz, V. (2012). Deconstructing the translation of psychological tests. Meta: Journal des traducteurs/Meta: Translators' Journal, 57, 715-739. Retrieved from https://www.erudit.org/fr/revues/meta/2012-v57n3-meta0694/1017088ar.pdf

Brislin, R. W. (1970). Back-translation for cross-cultural research. Journal of CrossCultural Psychology, 1(3), 185-216. Retrieved from http://journals.sagepub. com/doi/pdf/10.1177/135910457000100301

Bullinger, M., Alonso, J., Apolone, G., Leplège, A., Sullivan, M., Wood-Dauphinee, S., ... \& Fukuhara, S. (1998). Translating health status questionnaires and evaluating their quality: The IQOLA project approach. Journal of clinical epidemiology, 51, 913-923. Retrieved from http:/www.jclinepi.com/article/ S0895-4356(98)00082-1/pdf

Chidlow, A., Plakoyiannaki, E., \& Welch, C. (2014). Translation in cross-language international business research: Beyond equivalence. Journal of International Business Studies, 45, 562-582. Retrieved from https://ink.springer.com/article/ $10.1057 /$ jibs.2013.67

Davidov, E., Meuleman, B., Cieciuch, J., Schmidt, P., \& Billiet, J. (2014). Measurement equivalence in cross-national research. Annual Review of Sociology, 40, 55-75. Retrieved from http://www.annualreviews.org/doi/abs/ 10.1146/annurev-soc-071913-043137

Dean, E., Caspar, R., McAvinchey, G., Reed, L., \& Quiroz, R. (2007). Developing a low-cost technique for parallel cross-cultural instrument development: The Question Appraisal System (QAS-04). International Journal of Social Research Methodology, 10, 227-241.

Dept, S. (2013, July). Translatability assessment of draft questionnaire items. Paper presented at the European Survey Research Association Conference. Retrieved from https://www.europeansurveyresearch.org/conf/uploads/93/403/56/130716_ ESRA2013_Dept_TranslatabilityAssessment.pdf

Dillman, D. A., Smyth, J. D., \& Christian, L. M. (2008). Internet, mail, and mixedmode surveys: The tailored design method ( ${ }^{\text {rd }}$ ed.). Hoboken, NJ: John Wiley \& Sons.

Dorer, B. (2011). Advance translation in the 5th round of the European Social Survey (ESS). FORS Working Paper Series 2011-4. Lausanne: FORS. Retrieved from http://forscenter.ch/wp-content/uploads/2013/10/FORS_WPS_2011-04_Dorer3.pdf

Dorer, B. (2015). Carrying out 'advance translations' to detect comprehensibility problems in a source questionnaire of a cross-national survey. In K. Maksymski, 
S. Gutermuth, \& S. Hansen-Schirra (Eds.), Translation and comprehensibility (pp. 77-112). Berlin: Frank \& Timme.

Douglas, S. P., \& Craig, C. S. (2007). Collaborative and iterative translation: An alternative approach to back translation. Journal of International Marketing, 15, 30-43. Retrieved from http://journals.ama.org/doi/pdf/10.1509/jimk.15.1.030

EMT expert group. (2009). Competences for professional translators, experts in multilingual and multimedia communication. Retrieved from https://ec.europa. eu/info/sites/info/files/emt_competences translators_en.pdf

Fitzgerald, R., Widdop, S., Gray, M., \& Collins, D. (2011). Identifying sources of error in cross-national questionnaires: application of an error source typology to cognitive interview data. Journal of Official Statistics, 27, 569-599. Retrieved from http://www.jos.nu/Articles/abstract.asp?article=274569

Fowler, F. Jr., \& Cosenza, C. (2008). Writing effective questions. In E. de Leeuw, J. J. Hox, \& D. A. Dillman (Eds.), International handbook of survey methodology (pp. 136-160). New York: Lawrence Erlbaum Associates.

García Izquierdo, G., \& Borja Albi, A. (2008). A multidisciplinary approach to specialized writing and translation using a genre based multilingual corpus of specialized texts. LSP \& Professional Communication, 8, 39-64. Retrieved from http://repositori.uji.es/xmlui/bitstream/handle/10234/18993/30829.pdf?sequence $=1 \&$ isAllowed $=\mathrm{y}$

Göpferich, S., \& Jääskeläinen, R. (2009). Process research into the development of translation competence: Where are we, and where do we need to go? Across Languages and Cultures, 10, 169-191. Retrieved from http://akademiai.com/ doi/abs/10.1556/Acr.10.2009.2.1

Groves, R. M., Fowler, F.J. Jr., Couper, M. P., Lepkowski, J. M., Singer, E., \& Tourangeau, R. (2009). Survey methodology ( $2^{\text {nd }}$ ed.). Hoboken, NJ: John Wiley $\&$ Sons.

Hambleton, R. K. (2005). Issues, designs, and technical guidelines for adapting tests into multiple languages and cultures. In R.K. Hambleton, P. F. Merenda, \& C. D. Spielberger (Eds.), Adapting educational and psychological tests for crosscultural assessment (pp. 3-38). Mahwah, NJ: Lawrence Erlbaum Associates.

Hambleton, R. K., \& Zenisky, A. L. (2011). Translating and adapting tests for crosscultural assessments. In D. Matsumoto \& F. J. R. van de Vijver (Eds.), Crosscultural research methods (pp. 467-474). Cambridge: Cambridge University Press.

Harkness, J. (2003). Questionnaire translation. In J. Harkness, F. J. R. van de Vijver, \& P. Ph. Mohler (Eds.), Cross-cultural survey methods (pp. 35-56). Hoboken, NJ: Wiley \& Sons.

Harkness, J. (2008). Comparative survey research: Goal and challenges. In E. de Leeuw, J. J. Hox, \& D. A. Dillman (Eds.), International handbook of survey methodology (pp. 56-77). New York: Lawrence Erlbaum Associates.

Harkness, J., Pennell, B.-E. \& Schoua-Glusberg, A. (2004). Survey questionnaire translation and assessment. In S. Presser, J. M. Rothgeb, M. P. Couper, J. T. Lessler, E. Martin, J. Martin, \& E. Singer (Eds.), Methods for testing and evaluating survey questionnaires (pp. 453-473). Hoboken, NJ: Wiley \& Sons.

Harkness, J. \& Schoua-Glusberg, A. (1998). Questionnaires in translation. In J. Harkness (Ed.), ZUMA-Nachrichten Spezial 3: Cross-cultural survey equivalence (pp. 87-127). Mannheim: ZUMA. Retrieved from http://nbnresolving.de/urn:nbn:de:0168-ssoar-50967-7

Harkness, J., van de Vijver, F. J. R., \& Johnson, T. P. (2003). Questionnaire design in comparative research. In J. Harkness, F. J. R. van de Vijver, \& P. Ph. Mohler (Eds.), Cross-cultural survey methods (pp. 19-34). Hoboken, NJ: Wiley \& Sons.

Harkness, J. A., Villar, A., \& Edwards, B. (2010). Translation, adaptation, and design. In J. A. Harkness, M. Braun, B. Edwards, T. P. Johnson, L. Lyberg, P. P. Mohler, \& T. W. Smith, (Eds.). Survey methods in multinational, multiregional, and multicultural contexts (pp. 115-140). Hoboken: John Wiley \& Sons Inc.

International Test Commission. (2017). The ITC guidelines for translating and adapting tests $\left(2^{\text {nd }}\right.$ ed.). Retrieved from www.InTestCom.org

ISO (2015). ISO 17100: Translation services -- Requirements for translation services. Vernier: ISO. Retrieved from https://www.iso.org/standard/59149.html

Johnson, T. P. (1998). Approaches to equivalence in cross-cultural and cross-national survey research. In J. Harkness (Ed.). ZUMA-Nachrichten Spezial 3: Cross- 
cultural survey equivalence (pp. 1-40). Mannheim: ZUMA. Retrieved from http://nbn-resolving.de/urn:nbn:de:0168-ssoar-50967-7

Kenny, D. (1998). Equivalence. In M. Baker \& K. Malmkjær (Eds.), Routledge encyclopedia of translation studies (pp. 77-80). London: Routledge.

Kleiner, B., Pan, Y., \& Bouic, J. (2009). The impact of instructions on survey translation: An experimental study. Survey Research Methods, 3, 113-122. Retrieved from https://ojs.ub.uni-konstanz.de/srm/article/view/1563

Lynn, P., Japec, L. \& Lyberg, L. (2006). What's so special about cross-national surveys? In J.A. Harkness (Ed.), ZUMA-Nachrichten Spezial 12: Conducting cross-national and cross-cultural surveys (pp. 7-20). Mannheim: ZUMA. Retrieved from http://nbn-resolving.de/urn:nbn:de:0168-ssoar-49740-1

Mahadi, T. S. T., Vaezian, H., \& Akbari, M. (2010). Corpora in translation: A practical guide. Bern: Peter Lang.

Nord, C. (1997). A functional typology of translations. In A. Trosborg (Ed.), Text typology and translation (pp. 43-66). Amsterdam: John Benjamins Publishing.

Nord, C. (2014). Translating as a purposeful activity: Functionalist approaches explained. New York: Routledge.

Oude Voshaar, M. A., ten Klooster, P. M., Taal, E., Krishnan, E., \& van de Laar, M. A. (2012). Dutch translation and cross-cultural adaptation of the PROMIS $®$ physical function item bank and cognitive pre-test in Dutch arthritis patients. Arthritis Research \& Therapy, 14(2), 1-7. Retrieved from https://www.ncbi.nlm. nih.gov/pmc/articles/PMC3446413/pdf/ar3760.pdf

Ozolins, U. (2009). Back translation as a means of giving translators a voice. Translation \& Interpreting, 1(2), 1-13. Retrieved from http://trans-int.org/ index.php/transint/article/view/38

PACTE group (2005). Investigating translation competence: Conceptual and methodological issues. Meta, 50, 609-619. Retrieved from https://www.erudit. $\mathrm{org} / \mathrm{fr} /$ revues/meta/2005-v50-n2-meta881/011004ar/

Przepiórkowska, D. (2016). Translation of questionnaires in cross-national social surveys: A niche with its own theoretical framework and methodology. Między Oryginatem a Przekładem, 31, 121-135. Retrieved from http://www. akademicka.pl/index.php?detale $=1 \& \mathrm{a}=1 \& \mathrm{id}=35342$

Przepiórkowska, D., \& Zmijewska-Jedrzejczyk, T. (2013, July). Seeking equivalence in translating ends of survey scales: A corpus-based approach. Paper presented at the European Survey Research Association Conference. Retrieved from https://www.europeansurveyresearch.org/conference/programme?sess $=152 \# 578$

Schuman, H., \& Presser, S. (1981). Questions and answers in attitude surveys: Experiments in question form, wording, and context. New York: Academic Press.

Schwarz, N. (1997). Questionnaire design: The rocky road from concepts to answers. In L. Lyberg, P. Biemer, M. Collins, E. de Leeuw, C. Dippo, N. Schwarz, \& D. Trewin (Eds.), Survey measurement and process quality (pp. 27-45). New York: Wiley \& Sons.

Smith, T. W. (2003). Developing comparable questions in cross-national surveys. In J. Harkness, F. J. R. van de Vijver, \& P. Ph. Mohler (Eds.), Cross-cultural survey methods (pp. 69-91). Hoboken, NJ: Wiley \& Sons.

Tourangeau, R., Rips, L. J., \& Rasinski, K. (2000). The psychology of survey response. Cambridge. Cambridge University Press.

Wild, D., Eremenco, S., Mear, I., Martin, M., Houchin, C., Gawlicki, M. ... Molsen, E. (2009). Multinational trials - recommendations on the translations required, approaches to using the same language in different countries, and the approaches to support pooling the data: the ISPOR patient reported outcomes translation \& linguistic validation good research practices task force report. Value in Health, 12, 430-440. Retrieved from https://www.ispor.org/workpaper/patient_reported outcomes/Wild-Houchin.pdf 